\title{
The Study and Development of E-kanban Management in MES for Hardware Plastics Production Workshop *
}

\author{
Liping Zhang ${ }^{\mathrm{a}}$, Zhiping Wang, Baojian Wu, Jun Lib \\ ${ }^{1}$ Guangdong Institute of Automation; ${ }^{2}$ Guangdong Key Laboratory of modern control \\ technology; ${ }^{3}$ Guangdong Open Laboratory of Modern Control \& O-M-E Technology; ${ }^{4}$ Cloud \\ Computing Industrial Technology Innovation and Incubation Center, Chinese Academy of Sciences; \\ Guangzhou, China \\ ${ }^{5}$ School of Guangdong University of Technology \\ Guangzhou, China \\ alp.zhang@gia.ac.cn b523661602 @qq.com
}

Keywords-MES; Hardware Plastics Workshop; E-kanban Management; Production Control

\begin{abstract}
This paper introduces the development of Kanban management. Combined with the characteristics of hardware plastics industry's production process, it studies deeply ekanban management system in MES. And it focuses on the architecture, data flow, production control, information collection and other key technology of e-kanban management. E-kanban management realized the production transparence, could rapidly and timely to reflect changes in production processes, optimized the production management flow, greatly improved the production efficiency, and saved the cost, promoted the enterprise's management benefit.
\end{abstract}

\section{Introduction}

Entered in the twenty-first century, along with the development of information technology and all kinds of advanced manufacturing technology, workshop management information becomes more and more important. As an information system for workshop production management, MES (Manufacturing Execution System) can accurately schedule, track and monitor plant production information and process. It is a communication bridge between the upper production plan and the underlying device control. And it is the basic technical means for realizing the optimization of workshop production process. It plays an important role in strengthening the management and control of the production process in the workshop floor. As one of the core modules of MES, ekanban (Electronic kanban) management system can improve the controllability of the workshop process. It plays a large role on the construction of MES and the optimization of the whole workshop operation process. Therefore, research on the MES especially on the e-kanban management plays an important significance on the workshop production management, and on enhancing production and operational efficiency, and on upgrading the competitiveness of enterprise[1][2].

This paper introduces the development of kanban management. It studies the architecture of the e-kanban management under the background of the hardware and plastic manufacturing industry. And it focuses on the e-kanban management technology and its realization. The study of the paper makes the process of production much more transparent. Moreover, it links the whole production processes together and guarantees the production processes being in order. Besides, it can improve the abilities of data collecting, production monitoring and delivery of the plan and has important application value on promoting the product quality, beneficial efficiency and overall competitiveness. 


\section{Development Of Kanban Management}

Kanban management is an effective means for the Japanese Toyota Corporation to implement the pull production approach: JIT (Just in Time). And it is a kind of information tool, which is to regulate and control the production process and to achieve the target of producing the necessary quantity of the necessary products or parts in the necessary time.

Kanban management was created by the Toyota Corporation in Japan. After more than half a century of development and perfection, as a production management technology in pursuit of the production process rationality, efficiency and flexibility, kanban management has gradually been used by many enterprises of many industries in the world. Japanese Toyota Motor Corporation began to carry out workstation equipment card management in 1961, and it comprehensively used kanban management in the machine, forging, body, assembly workshop etc. in 1962. In the early 1970s, Japan began large-scale promotion of kanban management. And it was used in automobile, machinery manufacturing, electronics and computer industry etc. It has become an important part of Japanese industry competitive strategy. Western countries have begun to study the kanban management since 1980s and have a great development. They make the kanban management gradually evolve and develop into a more complete system of production management techniques and methods today, which including the management idea, production organization, quality management, logistics control, inventory management, cost control, site management, field improvement and so on.

With the development of information technology, e-kanban has been widely used. Many enterprises also use the kanban management combined with the ERP and MRP. That is, use the new management model, which using ERP to formulate the order plan, using MRP to maintain the materials requirements planning, and using kanban management to pull production, makes the kanban management have a new development. [2]-[13]

\section{The Research And Implementation Of E-kanban Management System}

\section{A. The Function Requirement of E-kanban Management System}

E-kanban is a visual bulletin board based on the computer network, and it has several functions as follows: 1, Optimizing the workshop material flow; 2, transferring production instruction; 3, collecting information; 4, tracking the quality of product, etc. E-kanban is an effective means for realizing the production process automation and digitization in mold workshop. Moreover, ekanban management system is mainly to achieve the following functions:

1) Set up a platform and mechanism for workshop information sharing, and realize the digital management and control on the workshop.

2) Associate with the ERP program, realize the network dispatching, and collect the production data, solve the information island and information gap problem.

3) Through the e-kanban, workshop production employees can issue material requirement information in time, which promotes the warehouse management.

4) By way of HMI (Human-machine interaction), the system can realize mold production statistics, employee output statistics, completion condition statistics, etc. It can also provide data support for the MES timely and accurately.

5) Supervise the whole production process of molding. Realize the precise cost control and the production process traceability.

\section{B. The Architecture of E-Kanban Management System}

Figure 1 describes the architecture of e-kanban management system, which includes support layer, application system layer and operation layer etc. Users contain the operators, administrators and policy makers; application layer includes the application software and hardware, which are for auxiliary enterprise operation. Hardware support includes computer, network, universal controller and special equipment etc. And software support includes database, operating system and the e- 
kanban software etc. Service layer includes system maintenance and training and other technical services activities, system operation and organization protection agencies, personnel, operational rules and so on.

The service layer is the foundation for the implementation of the project. The support layer is to ensure the system long-term correctly stable running. And it provides services directly or indirectly for the application system. The application layer is the e-kanban management system, which accepts the input from the users. And it has stepwise management and accounting, supports the implementation of the factory management, analysis and control.

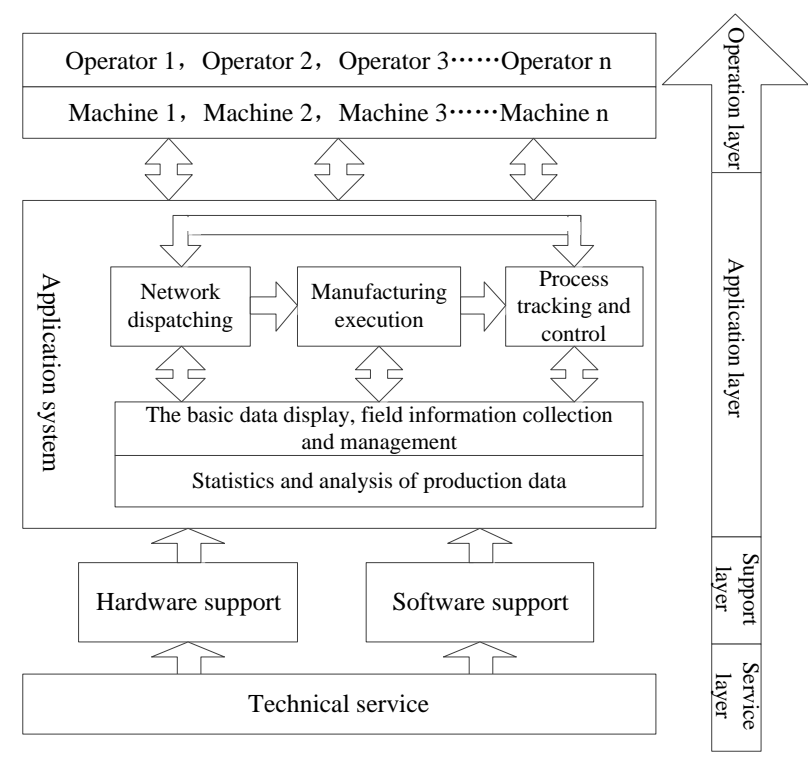

Figure 1. The architecture of e-kanban management system

C. The Solution of E-kanban Management System And Its Data Flow

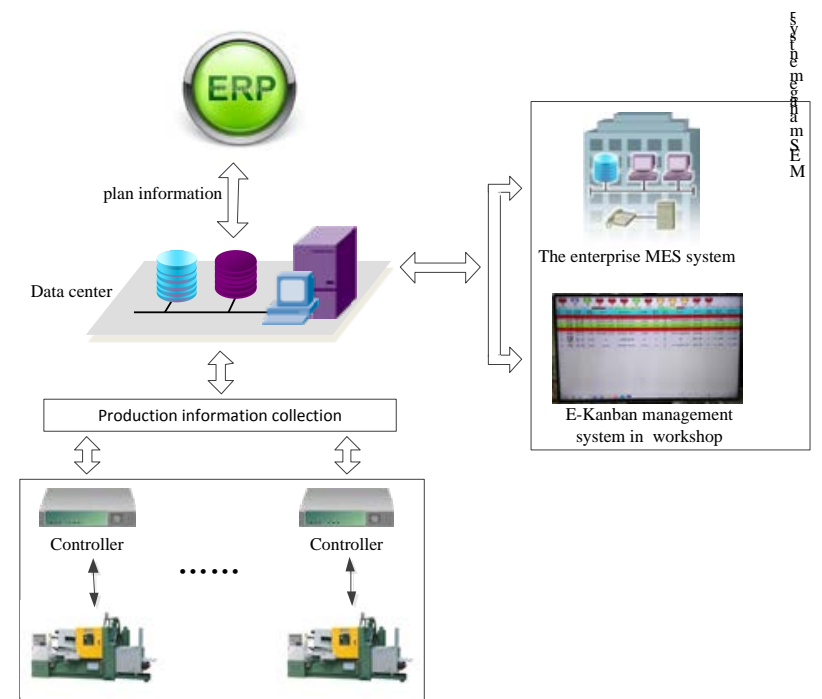

Figure 2. Solution and data flow of e-kanban management system

The solution and its data flow of e-kanban management system for the hardware plastics industry are presented in Figure 2. Platform and mechanism for workshop information sharing is the core of the solution. It links up ERP and stores production information collected by the device layer's universal controller. Meanwhile, it provides real-time accurate raw data for MES (including the ekanban system) and stores the statistical and analytical data. It is able to store and backup the complete production process information. And it is crucial for realizing network dispatching, manufacturing execution, process tracking and control. 


\section{Production Control Based on E-Kanban}

By ways of dispatching production task online, fetching material for each machine, collecting production information, tracking and controlling the production process, e-kanban system has achieved the production process automation and transparency. Its production operations control flow is shown in Figure 3.

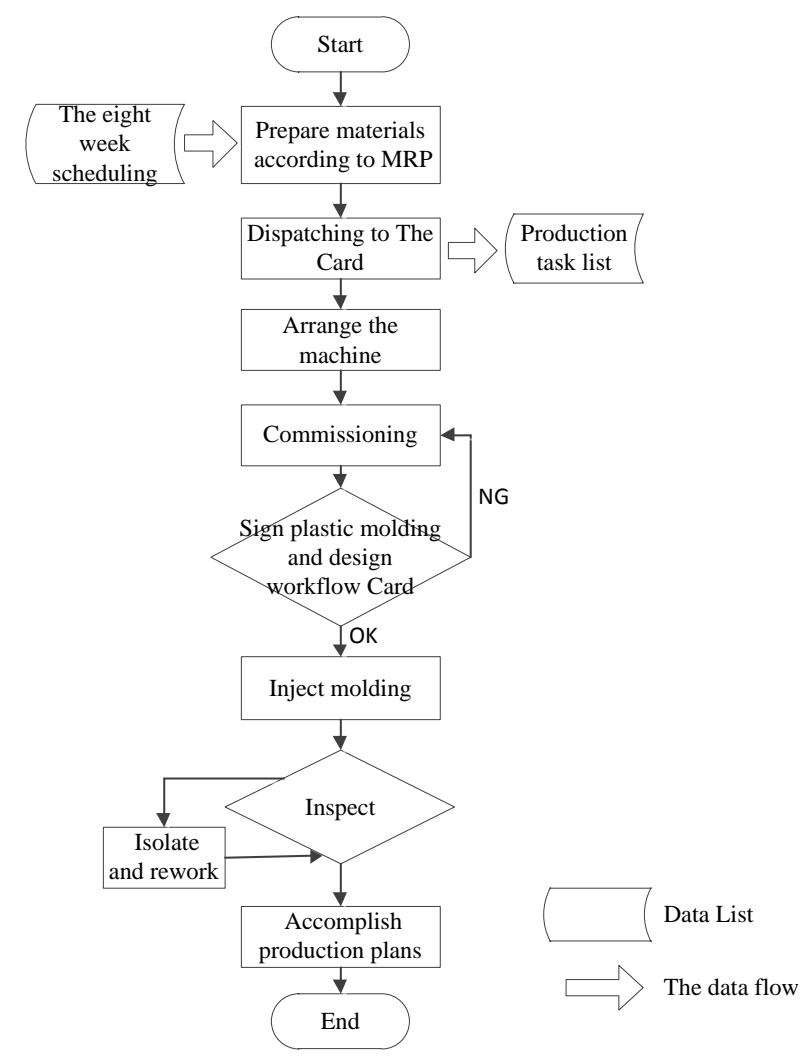

Figure 3. The flow chart for kanban to dispatch and produce

First of all, the PMC makes a production schedule for the next eight weeks, and coordinates with the leader to prepare. Then, the leader prepares materials according to the schedule requirement. System executives dispatch tasks to the card online. At the same time, the big electronic screen displays production task list. Leader arranges the machine. Then the technicians debug the equipment, do the first product self-inspections and automatically record the results. After the result is OK, the QC leader coordinates with the technicians to design the workflow card. Operators start to inject plastic molding according to the workflow card. Meanwhile the e-kanban management system automatically statistics staff workload, completion condition and production efficiency etc. and then displays these data in real-time. Finally, the QC staff inspects goods depending on the project. Non-conformity product will be isolated and redone. And conformity product will be packaged and loaded into the van by the material handler according to the JOB. 


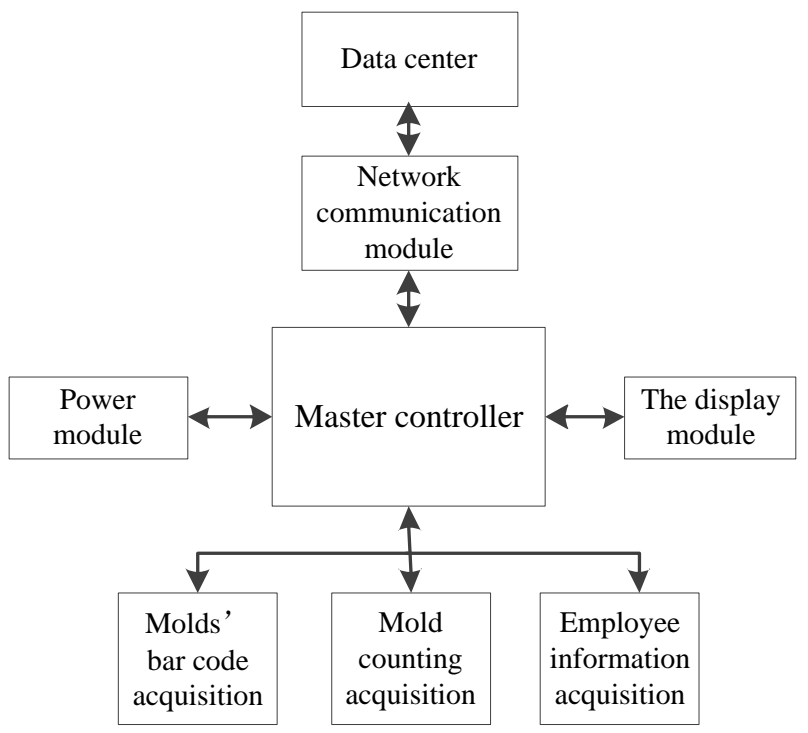

Figure 4. The hardware design diagram of universal controller

In the aspect of data acquisition, the system real-timely collects production data through the field universal controller, which was researched and developed by ourselves. The hardware design diagram of controller is illustrated in Figure 4. For both reliable and low-cost low-power requirements, the main controller uses STM32F103ZG microprocessor based on the core of ARM Cortex-M3. With the microprocessor, it collects information about molds' bar, mold counting, employee information etc. All the data collected is transferred to the data center through the network communication module, and then it is stored and analyzed. In addition, in order to facilitate the operator to observe the data, the system also sets the display module. The operator can observe the native data in a timely manner. Field controller is powered by the power supply module. [1], [14]

\section{F. Database Design}

Platform and mechanism for workshop information sharing is the core of the solution, while the database is its important part. It is the information storage of the e-kanban management system. The e-kanban system involves these data sheets: the system logs table, staff information table, employee work table, production schedule, card view table etc. Data structures for the main tables are presented in Figure 5.

\section{G. Development And Realization Of The E-kanban Management Software}

In Microsoft Visual Studio 2010, this paper built the e-kanban management software using C\# language. All this lay in the operating environment of Windows 764 bits. It used MS SQL Server 2008 R2 at the data center and used a 37 inch flat screen TV for display. With network, it realized the communication and data sharing. The display interface is shown in Figure 6. Display content can be customized according to the actual requirements of the workshop. In the hardware plastic industry, it includes the following contents: machines' state, attendance record, Item No., Mold No., the plan quantity, mold accumulated, employee accumulated, the Order No., employee name, average cycle, production efficiency, super injection molding rate and so on. 


\begin{tabular}{|c|c|c|c|c|c|c|}
\hline Item & Meaning & Data type & & Item & Meaning & Data type \\
\hline RQ & Logging dates & Datetime & & Time & Time & datetime \\
\hline SCXQPQID & $\begin{array}{c}\text { Production } \\
\text { schedule ID }\end{array}$ & Bigint & & {$[\log ]$} & Log & ntext \\
\hline CardNo & Staff No. & nvarchar(30) & & Item & Meaning & Data type \\
\hline Worktype & Job content & nvarchar(50) & & CardNo & Staff No. & nvarchar(30) \\
\hline CumulativeP & $\begin{array}{c}\text { Production quantity } \\
\text { of employee }\end{array}$ & Int & Staft work report & Name & Name & nvarchar(50) \\
\hline GMBH & Mold No. & nvarchar(50) & The system log & Worktype & Type of work & nvarchar(50) \\
\hline AverageCycle & Average period & Int & $\begin{array}{l}\text { Staff information } \\
\text { report }\end{array}$ & Pnl & The work No. & Int \\
\hline StartTime & Time on duty & Datetime & Production & Item & Meaning & Data type \\
\hline EndTime & Off-duty time & Datetime & schedule & $\mathrm{JH}$ & Machine No. & Int \\
\hline & & & Card view & Process & Machine state & nvarchar(20) \\
\hline Item & Meaning & Data type & & YGStartTime & Clock time & datetime \\
\hline PQRQ & Schedule date & Date & & StandardCycle & Standard cycle & Int \\
\hline $\mathrm{CPBH}$ & Product No. & nvarchar(255) & & СРBH & Item No. & nvarchar(50) \\
\hline JOBNO & The order No. & nvarchar(255) & & GMBH & Mold No. & nvarchar(50) \\
\hline LH_Q & Shipment date & Date & & ProductionPlan & The plan quantity & Int \\
\hline LJBH & The part No. & nvarchar(255) & & MlTotal & mold accumulated & Int \\
\hline GMBH & Mold No. & nvarchar(255) & & PS & $\begin{array}{c}\text { Employee } \\
\text { accumulated }\end{array}$ & Int \\
\hline JZ_ZQ & Standard cycle & Int & & JOBNO & The order No. & nvarchar(50) \\
\hline JZSCS_PCS & The plan quantity & Int & & $\mathrm{ZYY}$ & Staff name & nvarchar(50) \\
\hline POPS & The PO quantity & Int & & AverageCycle & Average cycle & Int \\
\hline YesNo & Finish or no & Bit & & $\mathrm{XL}$ & $\begin{array}{c}\text { The production } \\
\text { efficiency }\end{array}$ & nvarchar(20) \\
\hline ID & $\begin{array}{c}\text { Production } \\
\text { schedule ID }\end{array}$ & Bigint & & CPL & $\begin{array}{l}\text { Super inject } \\
\text { molding rate }\end{array}$ & nvarchar(20) \\
\hline
\end{tabular}

Figure 5. Data sheets and their structure

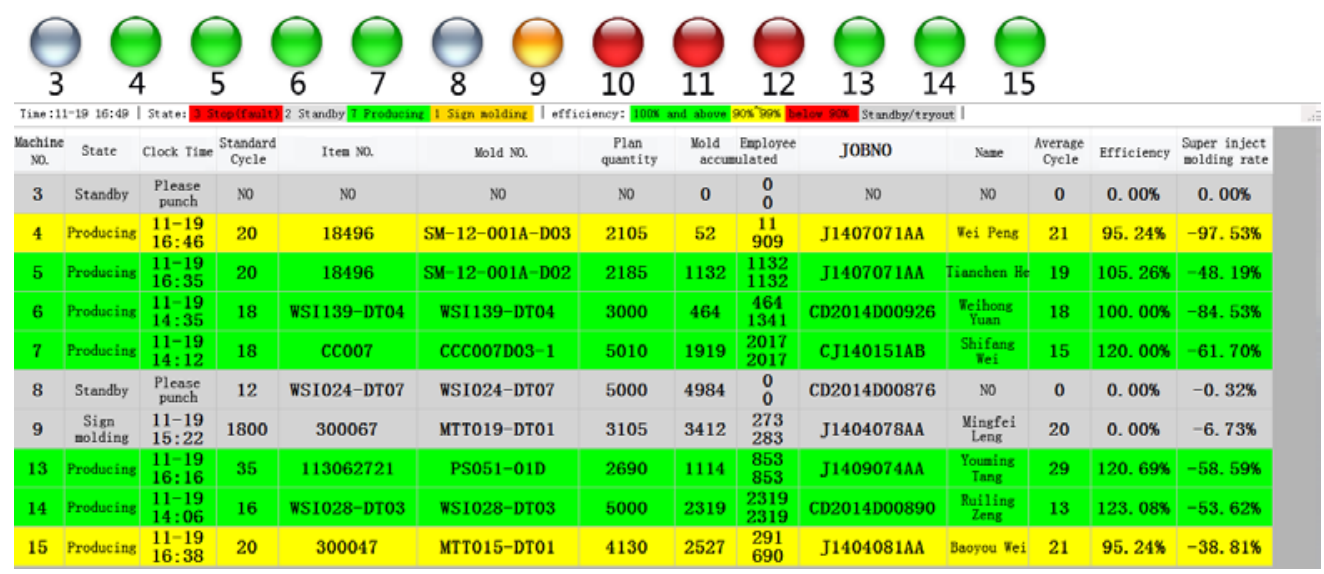

Figure 6. The display interface

\section{The Application Effect}

E-kanban management system has been successfully applied to an enterprise for processing hardware and plastic in Dongguan, a factory town in southeast china. It has reformed the enterprise's production workshop. By means of information technology, it realized the digital production, could rapidly and timely to reflect changes in production processes, optimized the production management flow, greatly improved the production efficiency, and saved the cost, promoted the enterprise's management benefit.

The company places great importance on the digital production in the workshop and gives great praise for the successful application of e-kanban management system in the traditional hardware plastic industry. In the communication on hardware and plastic industry, the company shared it as a 
typical case with the majority of hardware plastic enterprises and leaded peers to experience live effectiveness. They communicated with their applications and management experience, summarized and enhanced the advanced experience. It provided reference and developed ideas for promoting the deeper integration of industrialization and automation on traditional manufacturing.

\section{Conclusion}

Combined with the characteristics of the production process on hardware plastics industry, this paper studies deeply e-kanban management system in MES. And it focuses on the architecture, data flow, production control, information collection and other key technology of e-kanban management. It optimized the workshop production management processes, improved management quality and economic efficiency for the enterprise. It has provided an important guarantee for enterprises to realize the lean production and the agility of production, and has brought the new promotion for the information level of manufacturing industry on single order workshop's production management.

\section{* Supports}

This study gained the supports from: 1, Youth Science Research Fund of Guangdong Academy of Science in 2014 (project NO. qnjj201408); 2, Guangzhou science and technology plans in 2014 (Project NO. 2014J4500021); 3, Guangdong main scientific research institution innovation capability building special project in 2013. The project name is "small and medium-sized manufacturing enterprises MES cloud services platform”.

\section{References}

[1] Zhang Liping,Wu Baojian,Wang Zhiping,Wang Chunmei. Study on the MES Application in Hardware and Plastics Industry[J]. Automation \& Information Engineering, 2014, 35(1):45-48.

[2] Li Tiantao. Study and Development of E-kanban System in MES Oriented to Motor Mould Production[D]. Shandong University,2007.

[3] Steven Nahmias. Production and Operations Analysis, Sixth ed. Tsinghua University Press, 2009:335-387.

[4] Karmarkar, U. “Getting Control of Just-In-Time.” Harvard Business Review 67 (SeptemberOctober 1989), pp.122-31.

[5] Monden, Y. “What Makes the Toyota Production System Really Tick?” Industrial Engineering 13, no. 1 (1981a), pp.36-46.

[6] Monden, Y. “Adaptable Kanban system Helps Toyota Maintain Just-In-Time Production.” Industrial Engineering 13, no. 5 (1981b), pp. 28-46.

[7] Shingo, S. Study of “Toyota” Production System from Industrial Engineering Viewpoint. Tokyo: Japan Management Association, 1981.

[8] Zipkin, P. “Does Manufacturing Need a JIT Revolution?” Harvard Business Review 69 (January-February 1991), pp.40-50.

[9] Chhikara, J., and E. N. Weiss. “JIT Saving-Myth or Reality?” Business Horizons 38 (May-June 1995), pp.73-78.

[10] Carlson, R. C.; S. L. Beckman; and D. H. Kropp. "The effectiveness of Extending the Horizon in Rolling Production Scheduling.” Decision Science 13 (1982), pp. 129-46.

[11] Carlson, R. C.; J. V. Jucker; and D. H. Kropp. "Less Nervous MRP systems: A Dynamic Economic Lot-Sizing Approach.” Management Science 25 (1979), pp.754-61.

[12] Dixon, P. S., and E. A. Silver. "A Heuristic Solution Procedure for the Multi-Item, SingleLevel, Limited Capacity Lot Sizing Problem.” Journal of Operations Management 2 (1981), pp.23-39. 
[13] Hillier, F. S., and G. J. Lieberman. Introduction to Operations Research. 5th ed. New York: McGraw-Hill, 1990.

[14] Wang Tun,Mai Yuanzhen,Zou Bing,Wang Zhiping. Data Acquisition System for Die Casting Machine Based on STM32. Automation \& Information Engineering, 2014, 35(4):1-5. 